\title{
Thermal degradation behavior and physical properties for poly(methyl methacrylate) blended with propyl ester phosphazene
}

\author{
Bar-Long Denq, ${ }^{a}$ Yu-Shen Hu, ${ }^{a}$ Wen-Yen Chiu, ${ }^{a *}$ Leo-Wang Chen ${ }^{a}$ \& Yie-Shun Chiu ${ }^{b}$ \\ "Institute of Material Science and Engineering, National Taiwan University, Taipei, Taiwan, R.O.C. \\ ${ }^{b}$ Chemical System Research Division, Chung Shan Institute of Science and Technology, Taoyuan, Taiwan, R.O.C.
}

(Received 9 October 1996; accepted 27 December 1996)

\begin{abstract}
The physical properties, such as compatibility, the mechanical properties and the thermal degradation behavior of poly(methyl methacrylate) blended with propyl ester phosphazene have been investigated by DSC, SEM and TGA/FTIR. The results reveal partial miscibility of propyl ester phosphazene in PMMA when the amount of propyl ester phosphazene is less than $20 \mathrm{phr}$; greater amounts were immiscible. The major thermal degradation temperature, residual char yield and activation energy of PMMA blends increase with increasing propyl ester phosphazene content, and are higher than pure PMMA. (C) 1997 Elsevier Science Limited
\end{abstract}

\section{INTRODUCTION}

Poly(methyl methacrylate) (PMMA) exhibits excellent mechanical properties and good performance at various processing conditions. Since it is susceptible to degradation at high process temperatures, much work has been directed towards improving its thermal stability. For example, ${ }^{1-5}$ some studies have pointed out that PMMA blended with inorganic compounds such as chromium chloride and manganese chloride results in improved thermal stability. Other studies have shown that sulfur or phosphorus grafted in the polymer backbone could improve the thermal degradation behavior of PMMA. Fundamental studies ${ }^{6-8}$ on the degradation of PMMA have shown that the thermal degradation takes place by an unzipping reaction. This is accompanied by the evolution of methyl methacrylate gas with the reaction having an activation energy of $130 \sim 230 \mathrm{~kJ} / \mathrm{mol}$. Recently, studies on the thermal degradation of PMMA have also focused on avoiding the generation of toxic and corrosive gases during thermal degradation. This work has led to the substitution of halogen flame retardants by non-halogen compounds. The addition of these non-halogen

\footnotetext{
* To whom all correspondence should be addressed.
}

compounds is cheaper and more convenient than chemical modification; however, compatibility must be considered.

Among the current non-halogen compounds in use as flame retardants are a variety of phosphazene compounds." These compounds have been used mainly in non-burning expanded foam material. In other applications, large improvements in the thermal stability of rayon by the addition of phosphazene have been reported ${ }^{10}$ but studies on the thermal degradation of other polymers blended with phosphazene have not been reported. Hence, in this paper the effects of propyl ester phosphazene on the thermal degradation pathway of poly(methyl methacrylate) and its kinetics are examined by studying evolved gas products and residual yield using TGA/FTIR techniques. In addition, physical properties and compatibility are also discussed.

\section{EXPERIMENTAL}

\subsection{Blending material}

The samples were prepared from mixtures of poly(methyl methacrylate) (PMMA) supplied by 
Chi Mei Industrial Co. Ltd, and propyl ester phosphazene (FR) supplied by the Chang Shan Institute of Science and Technology. Samples were blended with acetone and prepared at room temperature by a solvent casting technique. The cast films were dried slowly in an oven at $106^{\circ} \mathrm{C}$ until the weight of the specimens remained unchanged. The physical properties of PMMA and propyl ester phosphazene are listed in Table 1, and the symbolic descriptions of the formulation used in this study are listed in Table 2.

\subsection{Measurement of phosphorus content}

The phosphorus content of the PMMA blends was determined using a colorimeter. ${ }^{1}$ The results were listed in Table 2.

\subsection{Glass transition temperature $\left(T_{\mathrm{g}}\right)$}

The glass transition temperature of the PMMA blends was determined using a Du Pont DSC 910 differential scanning calorimeter (DSC). The sample weights were 5-10 mg and the heating rate was $10^{\circ} \mathrm{C} / \mathrm{min}$ under nitrogen purge.

\subsection{Morphology observation}

The morphology and compatibility of PMMA blends were examined with a JEOL JSM-T100 scanning electron microscope (SEM) using an accelerating voltage of $5 \mathrm{kV}$.

\subsection{The interaction between PMMA and FR}

The interaction between poly(methyl methacrylate) and propyl ester phosphazene was investigated with a BIO-RAD $3240+$ FTS-40 Fouricr transform infrared spectrometer (FTIR).

\subsection{Mechanical properties of PMMA blends}

The tensile strength of the PMMA blends was measured using a UTM III-500 Instron according to ASTM 683.

\subsection{Thermal degradation behavior}

The thermal degradation of the PMMA blends was investigated with a Perkin-Elmer TGA-7 thermogravimetric analysis (TGA) at various heating rates under a nitrogen atmosphere.

\subsection{Evolved gas and residual char yield analysis}

The gas products of PMMA blends at various temperatures were studied using a SEIKO SSC 5000 thermogravimetric analyser (TGA) coupled with a BIO-RAD FTS-40 Fourier transform infrared spectrometer (FTIR). Samples were heated at a rate of $10^{\circ} \mathrm{C} / \mathrm{min}$ under a nitrogen atmosphere and the spectra were identified by visual analysis and by searching the spectral data bases. The residues at various temperatures in TGA were also investigated using a Fourier transform infrared spectrometer (FTIR BIORAD FTS-40).

\section{RESULTS AND DISCUSSION}

\subsection{Compatibility between PMMA and FR}

The relationship between the glass transition temperatures of PMMA blends and weight fraction of propyl ester phosphazene (FR) is illustrated in Fig. 1. The glass transition temperature of pure PMMA is $110^{\circ} \mathrm{C}$, which agrees with the literature. ${ }^{12}$ Since FR has a very low glass

Table 1. Physical properties of PMMA and propyl ester phosphazene

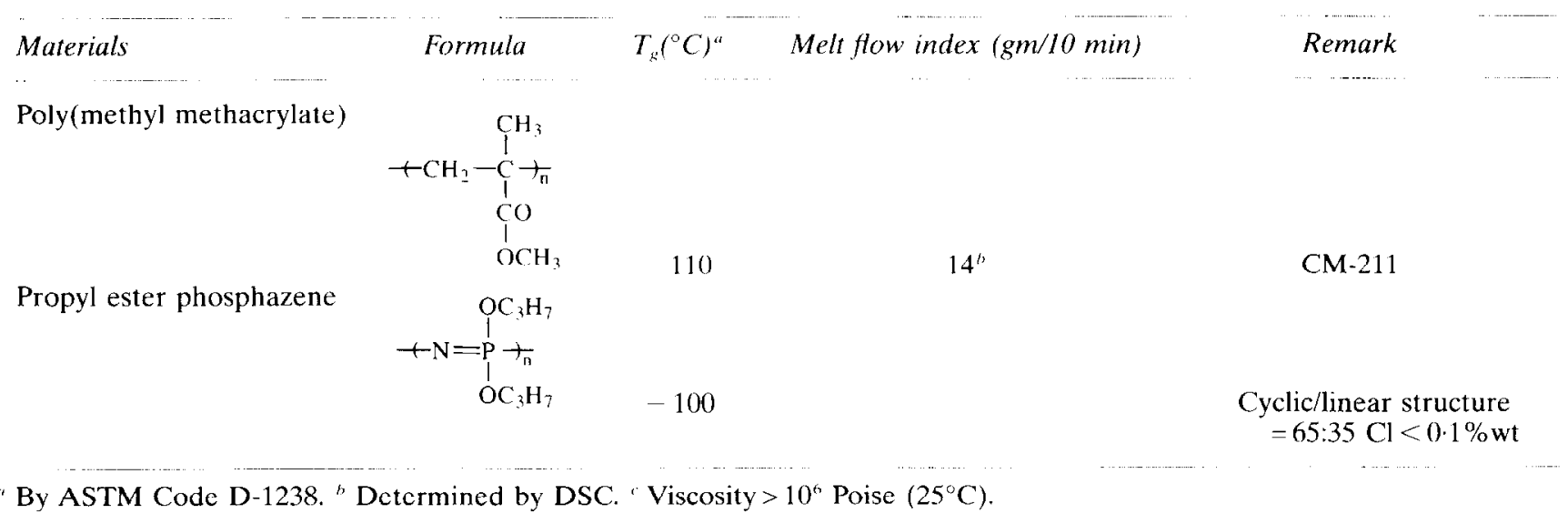


transition temperature $\left(-100^{\circ} \mathrm{C}\right)$, the glass transition temperature of PMMA blends decreases as the content of FR increases. However, the glass transition of PMMA blends begins to level off after $20 \mathrm{phr}$ of FR. This signals the incompatibility of FR in PMMA at levels greater than $20 \mathrm{phr}$. To verify this suspicion, scanning electron micrographs of the morphology of PMMA blends are shown in Fig. 2. The micrographs confirm that FR is uniformly dispersed in the PMMA matrix when the content of FR is less than $20 \mathrm{phr}$, Figs 2(a) and (b). At levels greater than 20 phr large particles are fromed which coagulate on the sample surface, and these particles increase in size with increasing FR content, Figs 2(c) and (d).

A comparison of experimental and theoretical glass transition temperatures calculated according to the Fox equation ${ }^{13}$ is listed in Table 3. The comparison indicates that the Fox equation is not applicable to the system of the PMMA-FR. This discrepancy between the Fox equation and the

Table 2. Symbolic meaning and phosphorus content of blended samples

\begin{tabular}{lccc}
\hline Code & Weight ratio $(P M M A / F R)$ & $P(w t \%)^{a}$ & $P(w t \%)^{b}$ \\
\hline PMMA0F & $10: 0$ & $0 \cdot 00$ & $<0 \cdot 01$ \\
PMMA1F & $10: 1$ & $2 \cdot 01$ & $2 \cdot 01$ \\
PMMA2F & $10: 2$ & $3 \cdot 68$ & $3 \cdot 70$ \\
PMMA3F & $10: 3$ & $5 \cdot 10$ & $5 \cdot 07$ \\
PMMA4F & $10: 4$ & $6 \cdot 31$ & $7 \cdot 17$ \\
FR & $0: 10$ & $22 \cdot 1$ & $22 \cdot 1$
\end{tabular}

"Phosphorus content from composition calculation. ${ }^{b}$ Phosphorus content by the colorimeter. experimental result is a further indication that PMMA blends are partially miscible when the FR content is less than $20 \mathrm{phr}$, but incompatible at levels greater than $20 \mathrm{phr}$.

\subsection{The interaction between PMMA and FR}

The FTIR spectra for FR and three different PMMA blends are shown in Fig. 3. These are accompanied by a listing of functional group frequencies in Table 4 . Intensities at $1225 \sim 1250$ and $900 \sim 1050 \mathrm{~cm}^{-1}$ are attributed to $\mathrm{N}=\mathrm{P}$ and $\mathrm{P}-\mathrm{O}-\mathrm{C}$ bonds, ${ }^{14}$ respectively. An intensity change or peak shift of the<smiles>CC(C)=O</smiles>

group $\left(1730 \mathrm{~cm}^{-1}\right)$ is a measure of the interaction between PMMA and FR. Since this peak does not change with increasing FR, we infer that a chemical bond was not formed or that only weak interaction exists in the PMMA blends.

\subsection{Tensile properties}

The stress and strain characteristics of PMMA blends are shown in Fig. 4. The results show that the tensile strength of PMMA blends decreases with increasing FR content. However, the ultimate strain of PMMA blends increases with increasing FR content. These results show that FR acts as a plasticizer for PMMA.

\subsection{Thermal degradation of PMMA blends}

Both Fig. 5 and Table 5 represent the relationship of residual weight fraction to temperature. The

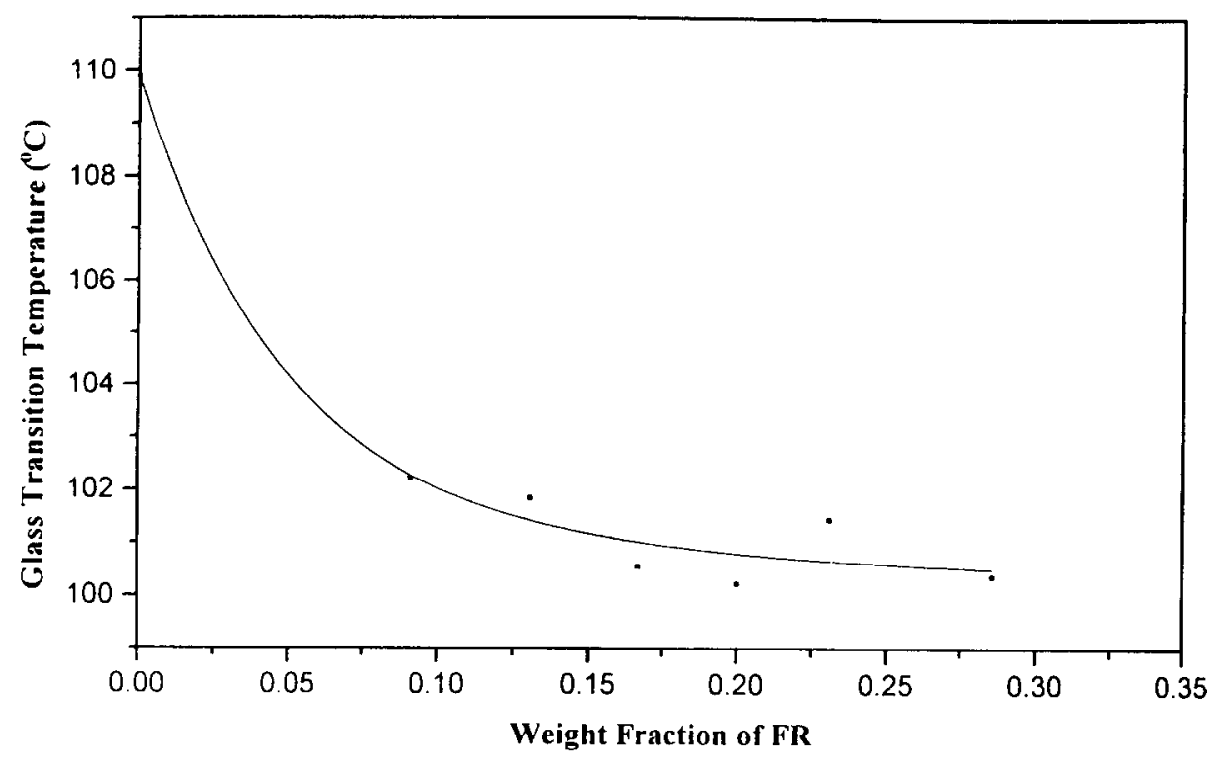

Fig. 1. The relationship of the glass transition temperature of PMMA blends versus the weight fraction of FR. 


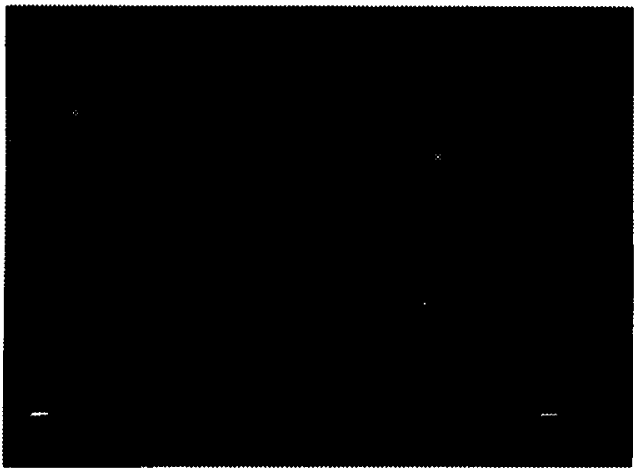

(a) PMMA0F

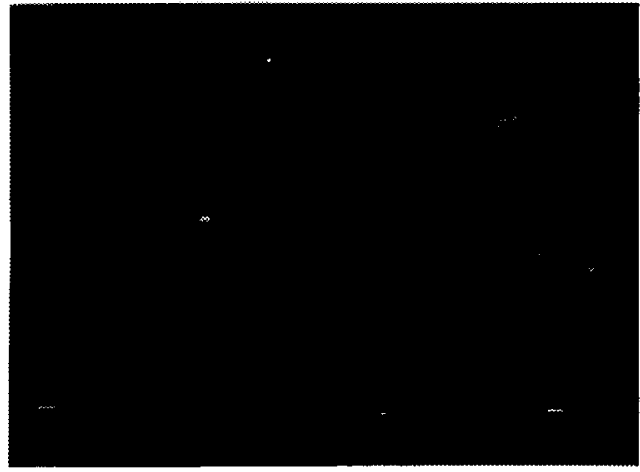

(b) PMMA2F

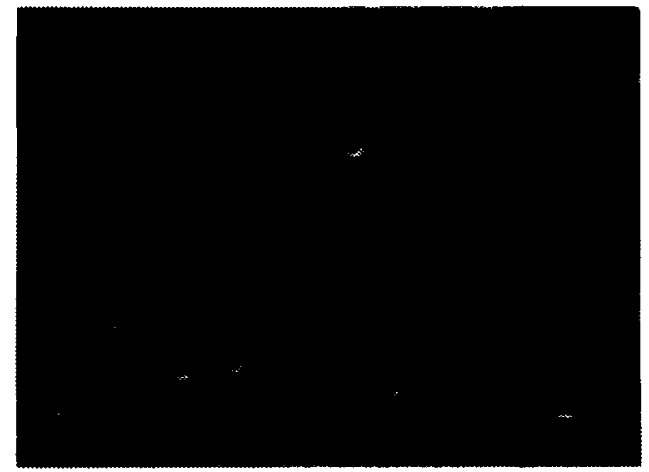

(c) PMMA3F

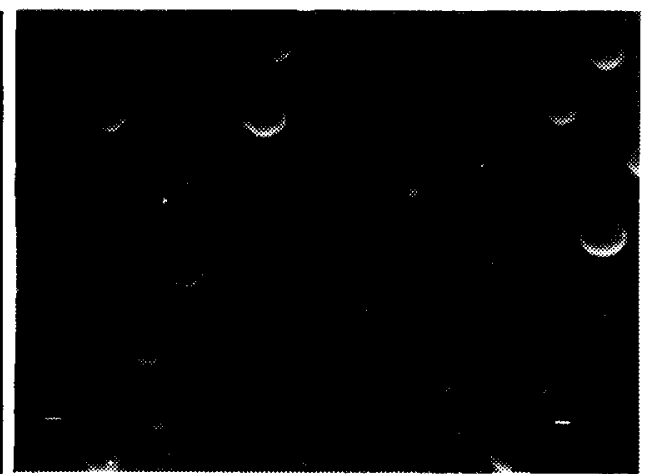

(d) PMMA4F

Fig. 2. Scanning electron micrographs of PMMA blends. (a) PMMA0F, (b) PMMA2F, (c) PMMA3F and (d) PMMA4F.

weight loss characteristics of various PMMA blends were recorded at heating rate of $10^{\circ} \mathrm{C} / \mathrm{min}$ under a nitrogen atmosphere. The curves show thermal degradation of FR occurring in three temperature ranges $-140-268^{\circ} \mathrm{C}, 270-340^{\circ} \mathrm{C}$ and above $340^{\circ} \mathrm{C}$. Gas discharge during the thermal degradation of FR and the FTIR spectrum at various times during that gas discharge are shown in Figs 6(a) and 7(a), respectively. The FTIR spectra in Fig. 7(a) are very similar all the way through the thermal degradation process by visual analysis and by searching the spectral data bases, and this spectral data led to the conclusion that the major gas product was propylene. The FTIR spectrum of the condensed phase of FR at

Table 3. Comparison of glass transition temperature between experimental results and calculation using the Fox equation

Weight fraction $T_{n}$ (experimental) $T_{4}$ (by Fox equation)
of FR in
PMMA blends

$\begin{array}{lll}0(0 \mathrm{phr}) & 110 & 110 \\ 0.09(10 \mathrm{phr}) & 102.22 & 71.95 \\ 0.13(15 \mathrm{phr}) & 101.85 & 57.67 \\ 0.17(20 \mathrm{phr}) & 100 \cdot 56 & 45.57 \\ 0.20(25 \mathrm{phr}) & 100 \cdot 25 & 35.20 \\ 0.237(30 \mathrm{phr}) & 101.45 & 26.21 \\ 0.29(40 \mathrm{phr}) & 100.39 & 11.40\end{array}$

various temperatures is shown in Fig. $8(\mathrm{a})$. The peaks at $2940,2900,2850$ and $1478 \mathrm{~cm}$ '. assigned to bending in methyl and methylene groups, decrease with increasing temperature. as does the peak associated with the $\mathrm{P}=\mathrm{N}$ bond at $1250 \mathrm{~cm}$ '. The intensity at $1400 \mathrm{~cm}$ due to the<smiles>C=NP(C)(C)=O</smiles>

bond $^{1+}$ increases with increasing temperature. This implies that the methyl and methylene groups of $\Gamma R$ gradually disappear, due to the formation of propylene gas. The $P=N$ bond undergoes an isomerization reaction during the thermal degradation of FR as it seeks a more thermally stable structure. The thermal degradation mechanisms of FR are suggested by Maynard 't $a l^{15}$ and Papkov et $a l^{\prime \prime}$ as follows:

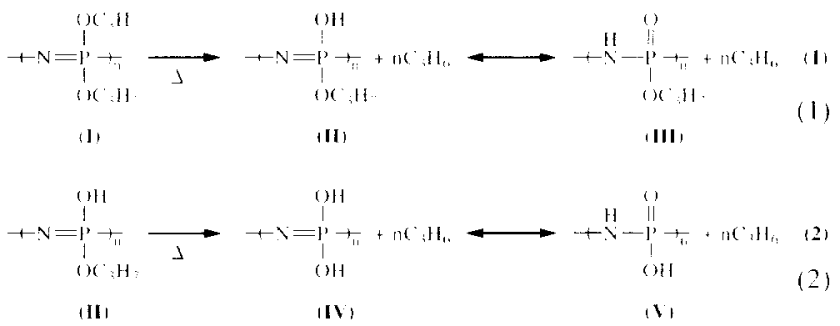

The amount of propylene produced during the thermal degradation of FR in eqns (1) and (2) are 


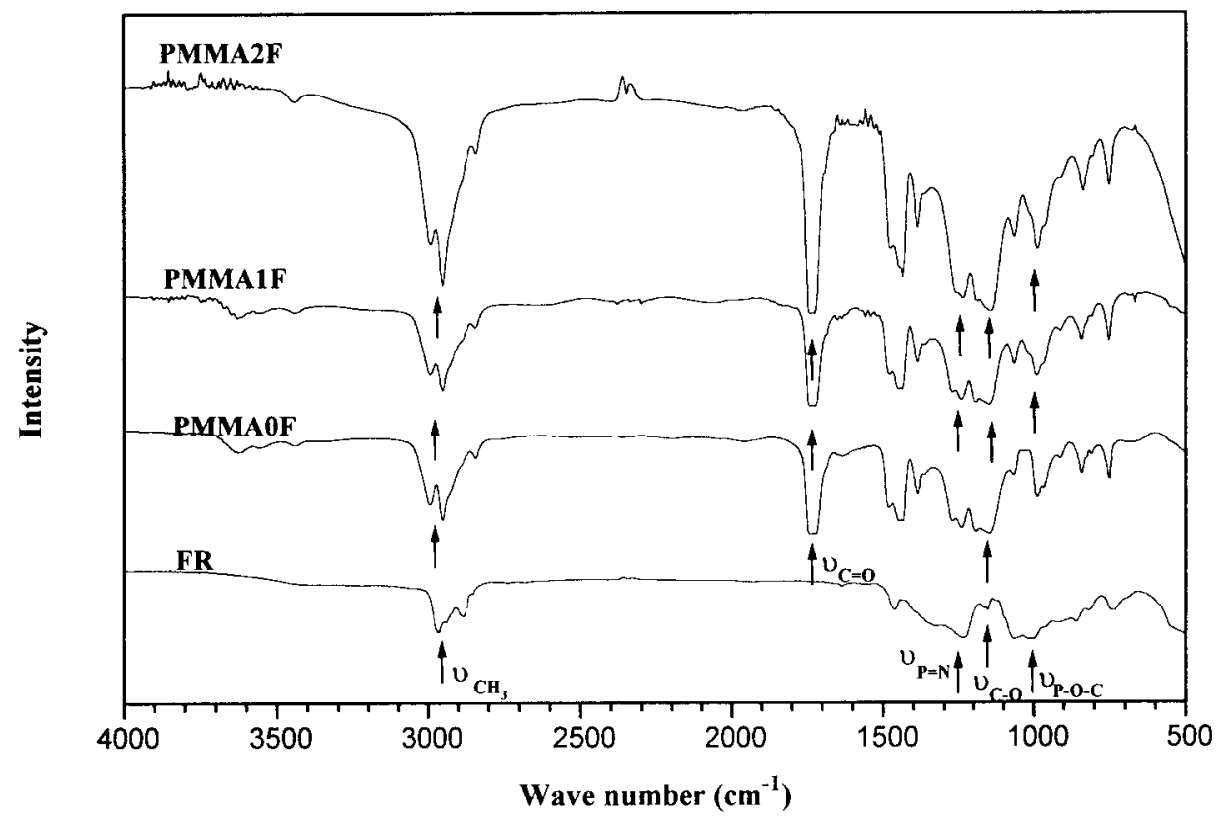

Fig. 3. FTIR spectra of various PMMA blends.

calculated to be 23 and $23 \mathrm{wt} \%$, respectively, but in fact from Fig. 5 the amount of propylene evolved during the thermal degradation of FR is 29 and $17 \mathrm{wt} \%$. Therefore, the thermal degradation of FR in stage 1 can be inferred to include eqn (1) and partially eqn (2), and the reaction occurring in stage 2 can be inferred to mainly follow eqn (2).

As shown in Fig. 5, the thermal degradation of PMMA, unlike FR, is a one stage reaction; the temperature range of the thermal degradation is between 289 and $453^{\circ} \mathrm{C}$. This agrees with Manring, ${ }^{6}$ Soloman ${ }^{7}$ and MacCallum ${ }^{17}$ who reported that the temperature range of thermal degradation of PMMA was between 270 and $410^{\circ} \mathrm{C}$. TGA/FTIR was also used to identify the pyrolysis gas of PMMA shown in Figs 6(b) and 7(b). The FTIR evidence shows that the major gas product at $35.6 \mathrm{~min}$ is methyl methacrylate. The result was determined by visual analysis and by searching spectral data bases, and it agrees

Table 4. Characteristics of FTIR for poly(methyl methacrylate) and propyl ester phosphazene

\begin{tabular}{lcc}
\hline Compound & Functional group & Frequency $\left(\mathrm{cm}^{-1}\right)$ \\
\hline $\begin{array}{c}\text { Poly(methyl } \\
\text { methacrylate) }\end{array}$ & $-\mathrm{C}=\mathrm{O}$ & 1730 \\
& $-\mathrm{C}-\mathrm{O}$ & $1150 \sim 1190$ \\
& $-\mathrm{CH}_{3}$ & 2962 \\
$\begin{array}{c}\text { Propyl cstcr } \\
\text { phosphazene }\end{array}$ & $\mathrm{N}=\mathrm{P}$ (linear) & $1260 \sim 1420$ \\
& $\mathrm{~N}=\mathrm{P}$ (cyclic) & $1120 \sim 1439$ \\
& $\mathrm{P}-\mathrm{O}-\mathrm{C}$ & $900 \sim 1050$
\end{tabular}

with the study of Guaita and Chianote. ${ }^{8}$ The FTIR spectrum of the condensed phase is similar to the original structure of PMMA as shown in Fig. 8(b). From the FTIR spectrum of evolved gas and residual yield, it can be predicted that the thermal degradation mechanism of thermal degradation of PMMA is unzipping reaction coupling with random-chain scission, which leads to monomer volatilization and depolymerization.

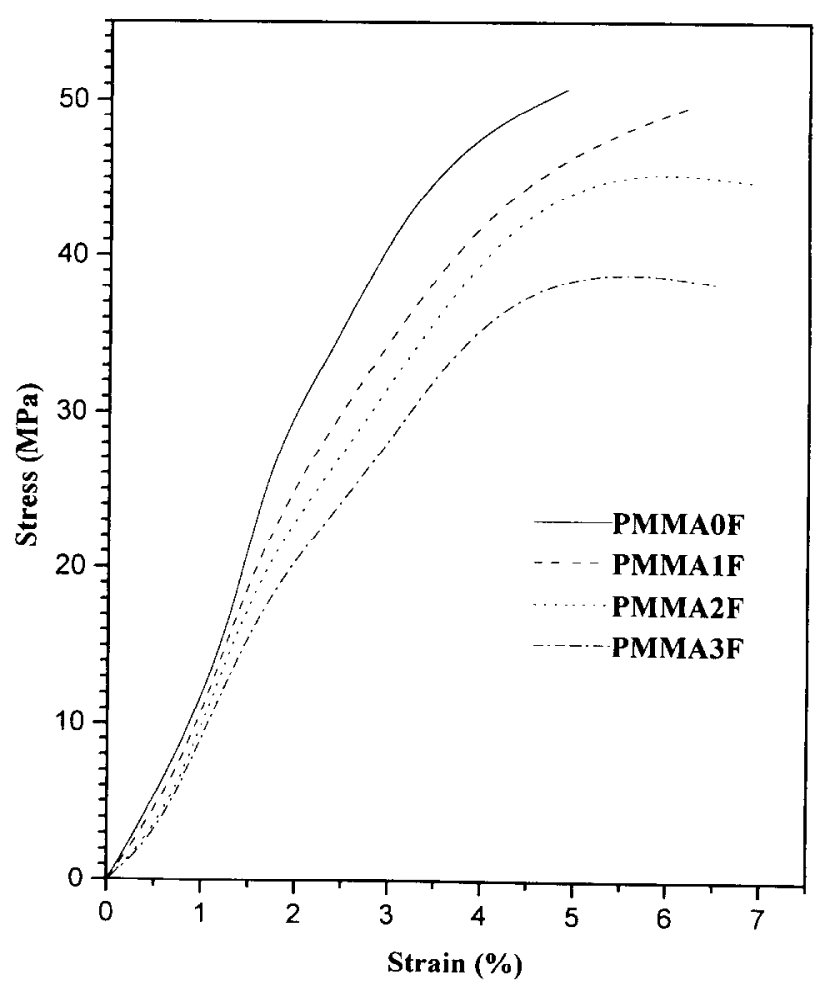

Fig. 4. Stress-strain curves of various PMMA blends. 


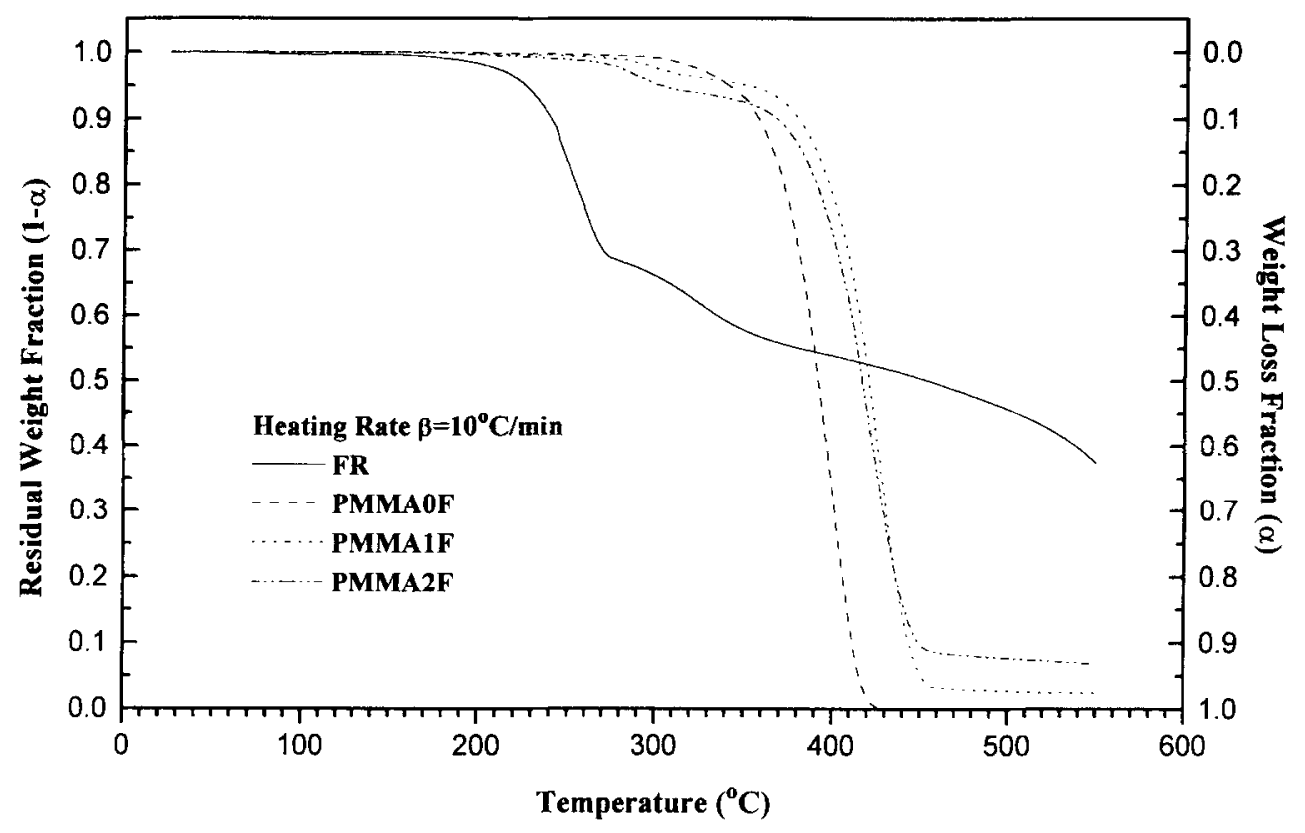

Fig. 5. TGA thermogram of PMMA blends at a heating rate of $10^{\circ} \mathrm{C} / \mathrm{min}$ under nitrogen atmosphere.

Table 5. Weight loss characteristics of various blends at a heating rate of $10^{\circ} \mathrm{C} / \mathrm{min}$ under nitrogen atmosphere

\begin{tabular}{lccccc}
\hline Blends & $T_{\text {smser }}\left({ }^{\circ} \mathrm{C}\right.$ ) at $5 \%$ wt loss & $\%$ residual at $550^{\circ} \mathrm{C}$ & $\begin{array}{c}\text { Temperature range for thermal } \\
\text { degradation }\left({ }^{\circ} \mathrm{C}\right)\end{array}$ \\
& & & Stage 1 & Stage 2 & Stage 3 \\
\hline FR & 224.98 & 37.47 & $140 \sim 268$ & $271 \sim 340$ & $340 \sim$ \\
PMMA0F & 340.08 & 0 & - & $289 \sim 453^{a}$ & - \\
PMMA1F & 351.95 & 2.43 & $220 \sim 331$ & $332 \sim 500^{a}$ & - \\
PMMA2F & 301.87 & 6.9 & $220 \sim 329$ & $337 \sim 500^{a}$ & -
\end{tabular}

"Major degradation of polymer or polymer blends.

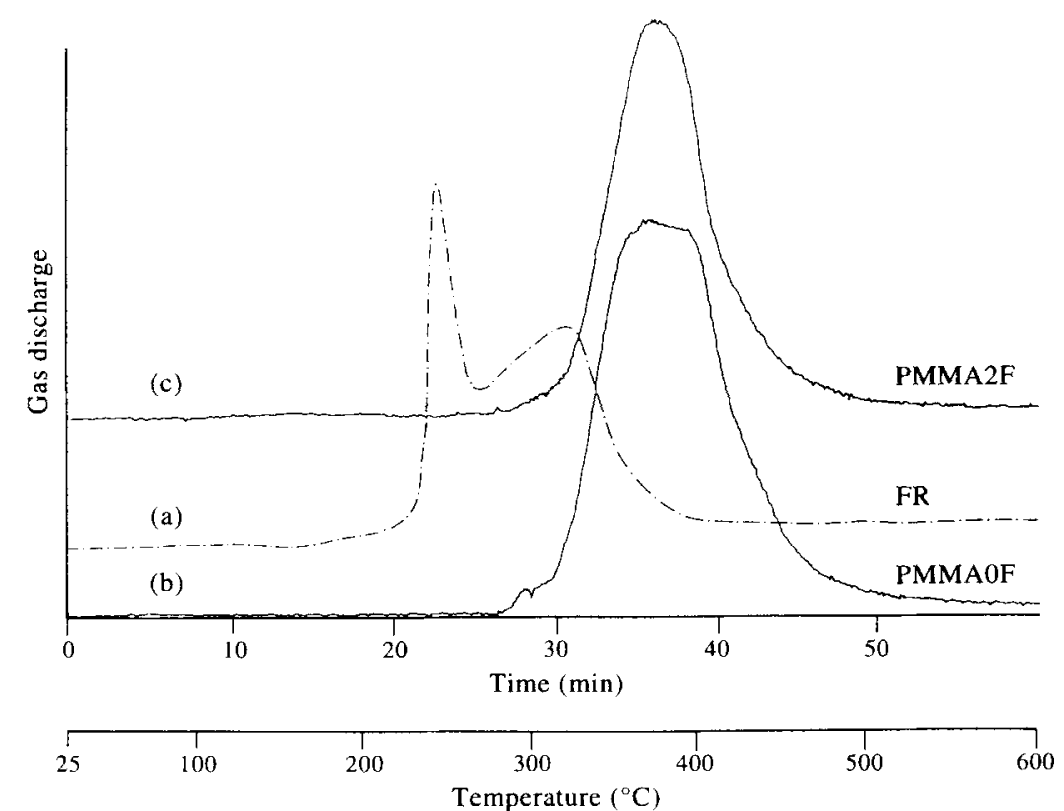

Fig. 6. The gas discharge with time (temperature) during thermal degradation for (a) FR, (b) PMMA0F and (c) PMMA2F. 
The thermal degradation of PMMA blends occurs in two stages as shown in Fig. 5. Weight loss occurring in the first stage, from 220 to $330^{\circ} \mathrm{C}$, is attributed to $\mathrm{FR}$, and weight loss during the second stage is mainly attributed to PMMA.
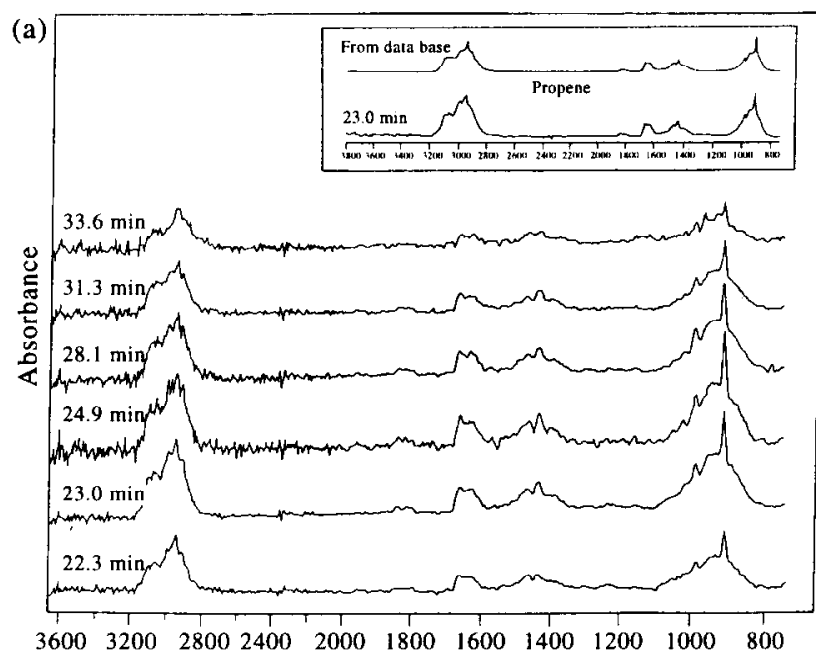
Wave number $\left(\mathrm{cm}^{-1}\right)$
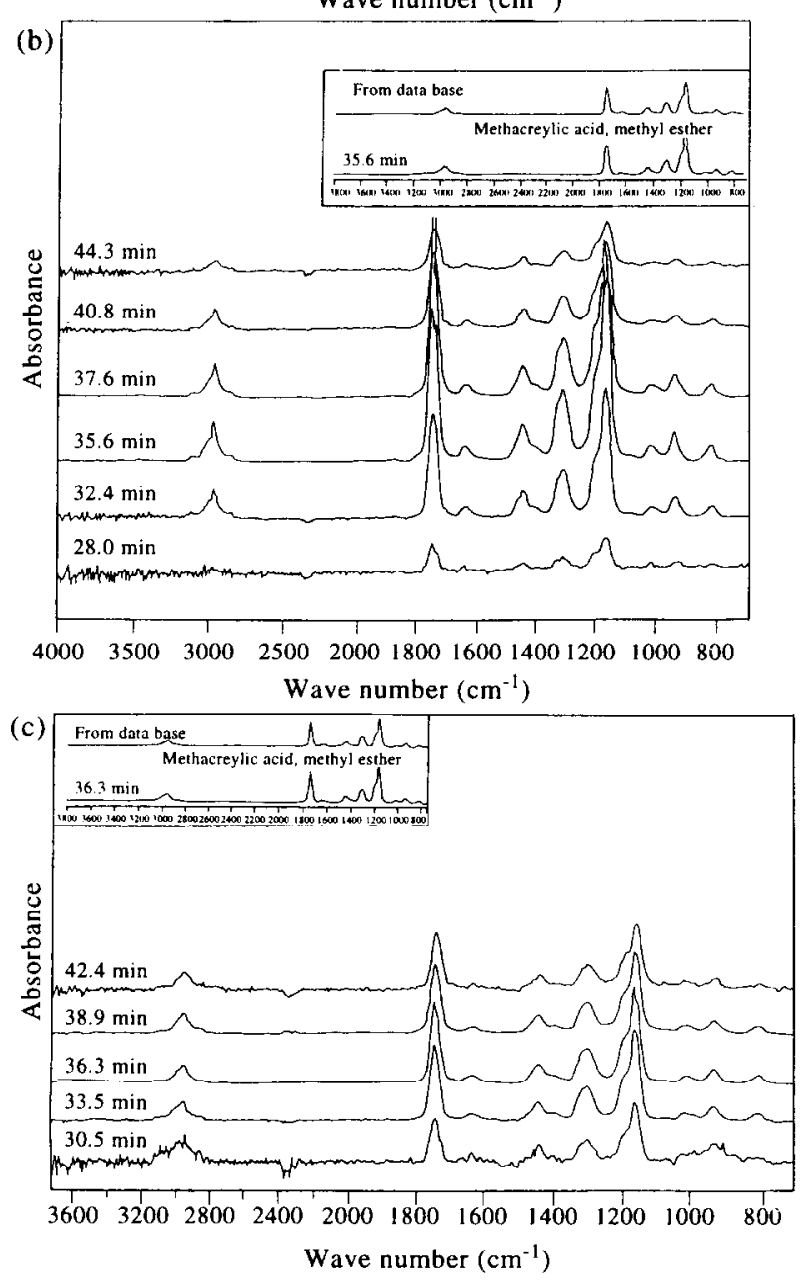

Fig. 7. FTIR spectrum of the gas phase during thermal degradation at various times for (a) FR, (b) PMMAOF and (c) PMMA2F.
Experiments to identify the gas product for PMMA blends are shown in Figs 6(c) and 7(c). The major evolved gas at $36.33 \mathrm{~min}$ is methyl methacrylate; propylene is not observed in the FTIR spectrum. The residual content of PMMA blends at $550^{\circ} \mathrm{C}$ increases with increasing $\mathrm{FR}$ content. It is interesting that the major degradation temperature of PMMA blends increases with increasing FR content.

From the FTIR spectrum of residual yield of PMMA2F shown in Fig. 8(c), it is found that the intensity of the<smiles>CC(C)=O</smiles>

bond at 1830 and $1750 \mathrm{~cm}^{-1}$ and the intensity of the<smiles>CC(=O)OC(C)=O</smiles>

bond at $1000 \mathrm{~cm}^{-1}$ increase are clearly seen at temperatures of 250 and $400^{\circ} \mathrm{C}$. This implies that residual yield forms an anhydride structure during the thermal degradation process of PMMA blends. However, the intensity at 1830 and $1750 \mathrm{~cm}^{-1}$ due to the contribution of anhydride mostly disappear at $400^{\circ} \mathrm{C}$, because the major degradation of PMMA occurs. In order to examine the degree of interaction between PMMA and FR during the thermal degradation of PMMA blends, a mixing rule, eqn (3), which assumed no interaction effect, was employed.

$$
W_{\text {blend }}(T)=W_{\text {PMMA }}(T) \cdot X_{\text {PMMA }}+W_{\mathrm{FR}}(T) \cdot X_{\mathrm{FR}}
$$

where

$$
\begin{array}{ll}
W_{\mathrm{blend}}(T): & \begin{array}{l}
\text { residual weight fraction of PMMA blend } \\
\text { at any temperature }
\end{array} \\
W_{\mathrm{PMMA}}(T): \begin{array}{l}
\text { residual weight fraction of pure PMMA } \\
\text { at any temperature } \\
\text { residual wcight fraction of FR at any tem- } \\
\text { perature } \\
W_{\mathrm{FR}}(T):
\end{array} & \begin{array}{l}
\text { weight fraction of PMMA at blends } \\
X_{\mathrm{PMMA}}:
\end{array} \\
X_{\mathrm{FR}}: & \text { weight fraction of FR at blends. }
\end{array}
$$

A comparison of the experimental result and the results calculated from the mixing rule is shown in Fig. 9. The major thermal degradation temperature predicted by the mixing rule is lower than the experimental results; however, the residual content predicted by the mixing rule is close to the experimental results after complete 

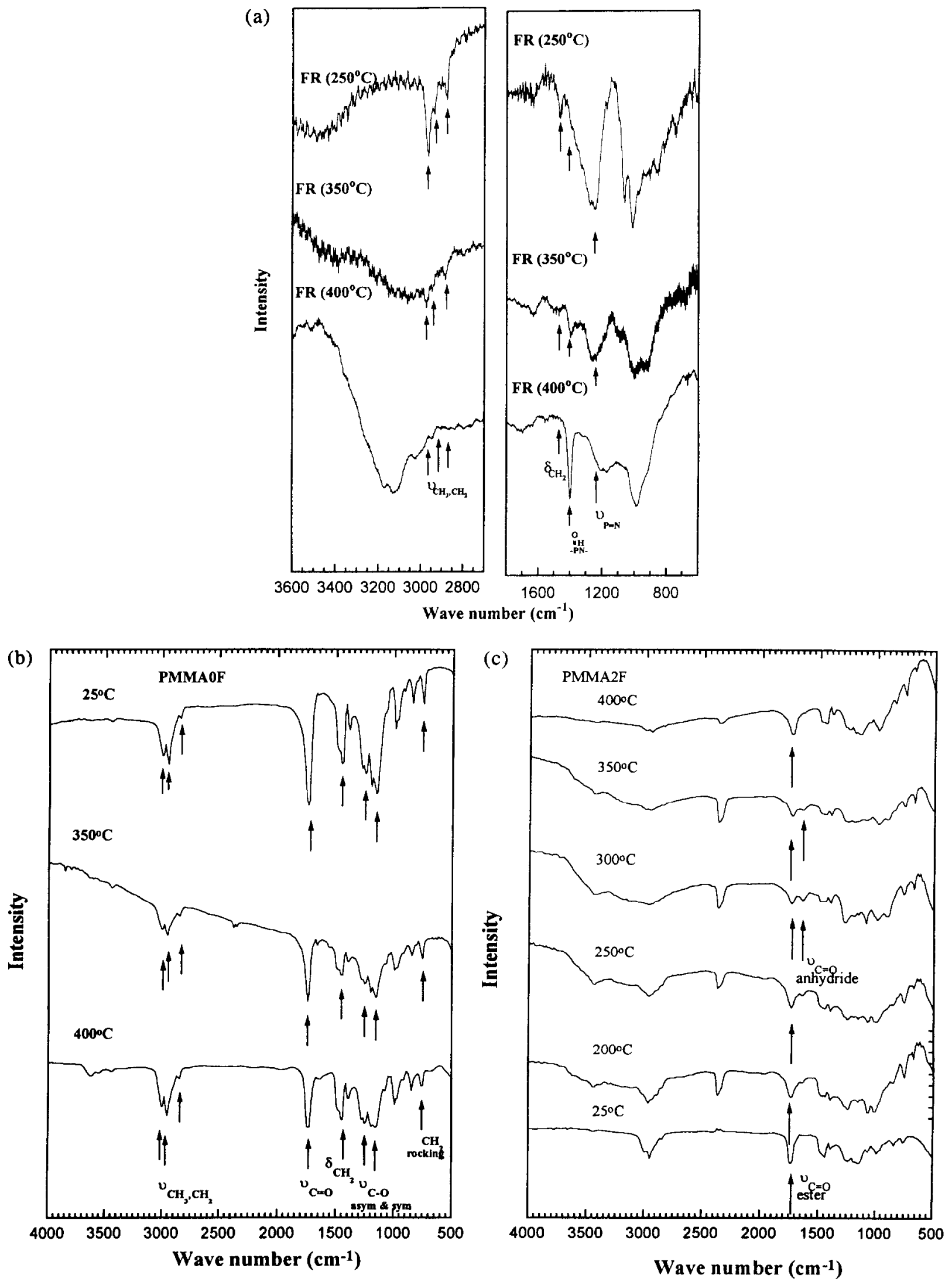

Fig. 8. FTIR spectrum of the condensed phase during thermal degradation at various temperatures: (a) FR. (b) PMMAOF and (c) PMMA2F 


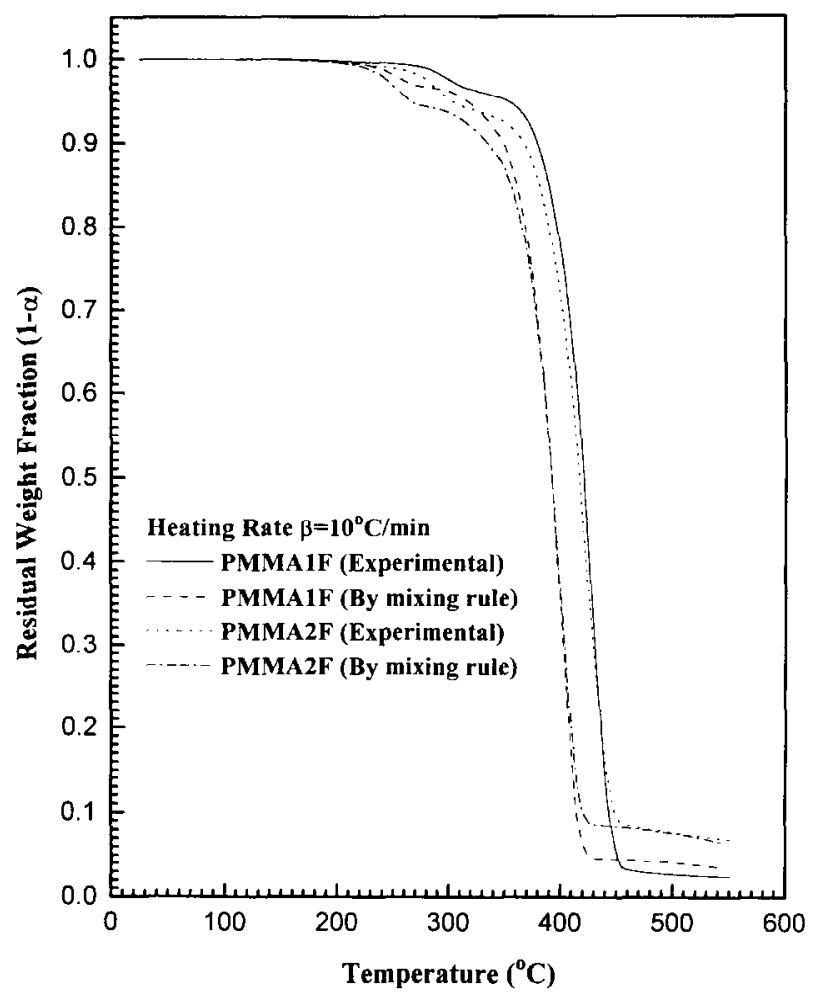

Fig. 9. Comparison of the TG $\Lambda$ thermograms between experimental results and mixing rule for PMMA1F and PMMA2F.

thermal degradation of PMMA. The incorporation of FR in PMMA polymeric chains accelerates the breakage of ester groups in the early stages of thermal degradation. In a later stage an anhydride structure is formed which retards the successive degradation. It seems that FR changes the thermal degradation reaction route, but it does not influence the major evolved gas of PMMA blends or form extra stable char with PMMA through the interaction.

\subsection{Kinetic analysis}

The relationship between apparent activation energy and weight loss fraction $(\alpha)$ of PMMA blends was determined using Ozawa's method. ${ }^{18}$ The results are shown in Fig. 10. The literature $^{6.19 .20}$ has pointed out that the range for the activation energy of PMMA is about $130 \sim 233$ $\mathrm{kJ} / \mathrm{mol}$. This includes random scission initiation and end initiation. In our experiment, the activation energy of PMMA increases with increasing weight loss fraction. The range is from $130 \sim 170 \mathrm{~kJ} / \mathrm{mol}$ and the average activation energy is $154 \mathrm{~kJ} / \mathrm{mol}$. Because the thermal degradation of FR occurs in three stages, the thermal degradation activation energy also has three stages. The first stage occurs between 100

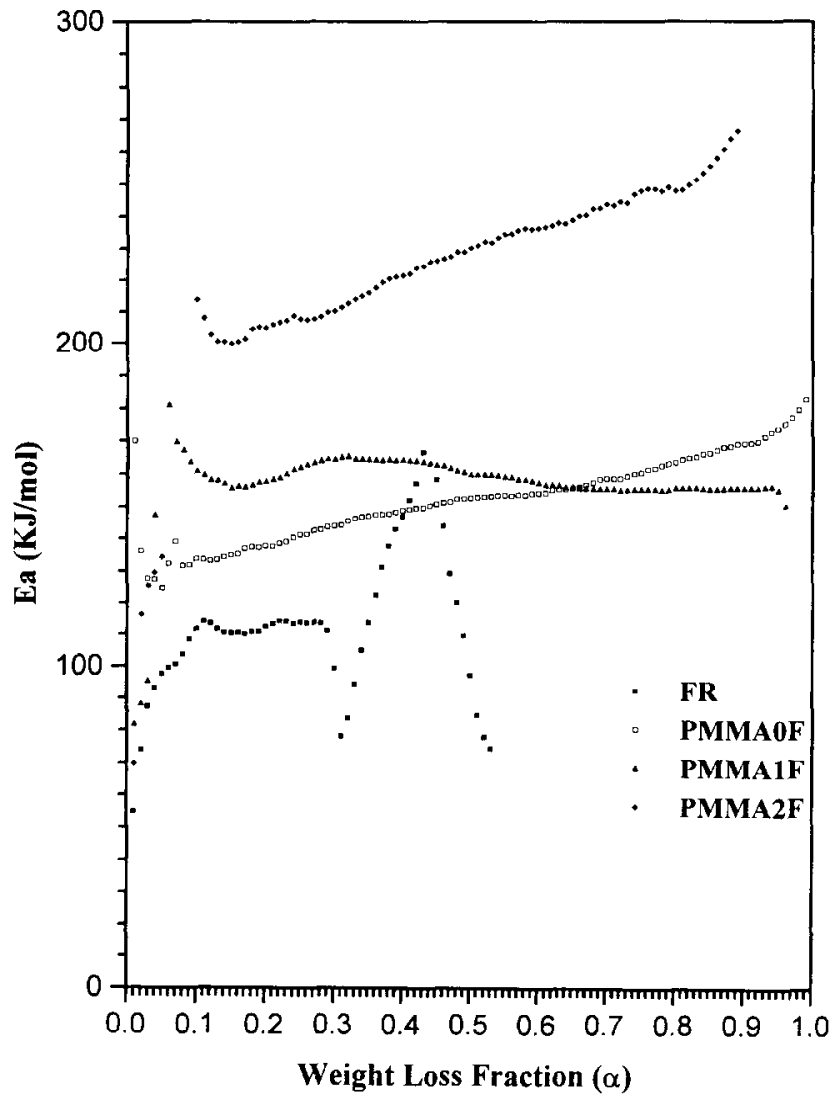

Fig. 10. The relationship of activation energy versus weight loss fraction for PMMA blends.

and $120 \mathrm{~kJ} / \mathrm{mol}(\alpha=0.04 \sim 0 \cdot 29)$ with an average value of $110 \mathrm{~kJ} / \mathrm{mol}$. Different competing reactions caused the range of activation energy for the second and third stages to become less well defined and so their physical meaning is less clear. The activation energy of thermal degradation of PMMA blends increases with increasing content of FR, and for 10 and $20 \mathrm{phr}$ blends the average activation energy is 170 and $221.4 \mathrm{~kJ} / \mathrm{mol}$, respectively. The increase in activation energy for the blends indicates that thermal degradation is delayed by the addition of FR.

\section{CONCLUSIONS}

1. Mechanical tests and electron microscope evidence indicate that PMMA and FR are partially miscibile when the content of FR is less than $20 \mathrm{phr}$.

2. The thermal degradation of FR occurs in three stages up to $550^{\circ} \mathrm{C}$, and propylene is the major 
evolved gas. The activation energy ranges from 100 to $120 \mathrm{~kJ} / \mathrm{mol}$ (weight loss fraction $\alpha=0.04 \sim 0.29$ ).

3. The thermal degradation of PMMA is a one stage reaction, and the major gas product is methyl methacrylate. The activation energy ranges from 130 to $170 \mathrm{~kJ} / \mathrm{mol}$ and average value is $154 \mathrm{~kJ} / \mathrm{mol}$.

4. The thermal degradation of PMMA blends occurs in two stages. Residual char yicld and activation energy are increased with increasing FR content.

5. The addition of FR in PMMA does not influence the major evolved gas or form extra char with PMMA though interaction, but it does delay the major degradation temperature.

\section{ACKNOWLEDGEMENTS}

The authors thank Mr Marc DeRosa for his correction and the Chung Shan Institute Science Technology (CSIST), Taiwan, R.O.C. for their financial support.

\section{REFERENCES}

1. Wilkie, C. A. Thomsen, J. R. and Mittleman, M. L., J. Appl. Polym. Sci., 1991, 42, 901

2. Wilkie, C. A. Leone, J. T. and Mittleman, M. L., J. Appl. Polym. Sci., 1991, 42, 1133

3. Beer, R. S. Wilkie, C. A. and Mittleman, M. L., J. Appl. Polym. Sci, 1992, 46, 1095

4. Reghunadhan Nair, C. P. Glouet, G. and Guilbent, Y., Polym. Degrad. Stab., 1989, 26, 305

5. Glouet. G. Knipper, M. and Brossas, J., Polym. Degrad. Stab., 1987, 17, 151

6. Manring, L. E., Macromolecules, 1991, 24, 3304

7. Solomon, D. H., J. Macromol. Sci. Chem., 1982, 17, 337

8. Guaita, M. and Chianote, O., Polym. Degrad. Stab., 1985. 11, 167

9. Allcock, H. R., Comprehensive Polymer Science, Vol. 4. Pergamon Press, Oxford, 1989, p. 527.

10. Toy, D. F. and Walsh, E. N., Phosphorus Chemistry in Everyday Living. American Chemical Society, 1987.

11. Tomson, M. B. Barone. J. P. and Nancollars, G. H., Atomic Absorption Newsletter, 1977, 16, 117

12. Brandrup, J. and Immergut, E. H., Polymer Handbook. Wiley-Interscience, New York, 1989.

13. Fox, T. G., Bull. Am. Phys. Soc., 1965, 1, 123

14. Halmann. M. Analytical Chemistry of Phosphorus Compounds. Wiley-Interscience, New York, 1972.

15. Maynard, S. J. Sharp. T. R. and Haw. J. F., Macromolecules, 1991, 24, 2794

16. Papkov, V. S. IL'ima, M. N. Tur, D. R. and Slonimskii, G. L., Polym. Sci. U.S.S.R., 1989, 31, 2509

17. MacCallum. J. R., Makromol. Chem., 1965, 83, 137

18. Ozawa, T., Bull. Chem. Soc. Jpn, 1965, 38, 1881

19. Brockhaus, V. A. and Jenckel. E., Makromol. Chem. $1956, \mathbf{1 8 / 1 9}, 262$

20. Madorsky. S. L.. J. Polym. Sci., 1953, 11, 491 